Rev. Elev. Méd. vét. Pays trop. 1967 20, 2 (345-347)

\title{
Entérite hémorragique aiguë à Welchia perfringens chez des zébus du Sénégal
}

\author{
M. P. DOUTRE
}

\begin{abstract}
RÉSUMÉ
Des cas d'entérite hémorragique aiguë à Weichia perfringens de type A sont apparus soudainement chez les zébus gobra adultes introduits dans un ranch pour y être engraissés avant l'abattage. Sur un troupeau d'environ 50 têtes, 17 ont succombé d̀ la maladie. La souche isolée s'est révélée très pathogène pour le cobaye par voie intra-musculaire et la loxine de culture faiblement hémolytique pour les hématies de mouton. La consommation de paille d'arachide ancienne et partiellement moisie, est rendu responsable de l'affection.
\end{abstract}

Depuis une quinzaine d'années, le rôle pathogène dans l'espèce bovine du genre Welchia a souvent été signalé, notamment en Europe $(2,4)$ et en Amérique du Nord (1) et du Sud (3), les affections décrites revêtant le plus souvent le caractère d'atteintes suraıguës ou aiguës provoquant hépatites, néphrites, hépato-néphrites, entérites, entéro-toxémies, etc...

$\mathrm{Si}$ la plupart des types de Welchia perfringens ont pu être incriminés, le type $A$ a été de toute évidence le plus souvent mis en cause.

Par contre, la bibliographie n'a jusqu'ıci jamais fait mention d'affections imputables, chez les bovins, en Afrique tropicale à des germes du groupe Welchio. Les caractères de l'élevage et le manque de moyens d'observation expliquent en partie cette absence de description. Les pathologistes concentrent en effet le plus souvent leur attention sur les grandes maladies infectleuses enzootiques virales, microbiennes ou parasitaires : peste et péripneumonie bovines, charbon bactéridien, pasteurellose ef salmonellose, trypanosomiases etc... Parmi les maladies dues aux microbres anaérobıes, seul le charbon symptomatique à Clostridium chauver ou à Clostridium septicum a fait l'objet d'une prophylaxie systématique. Le tétanos ne donne lieu qu'à de rares observations chez le cheval, le mouton et le singe maintenu en captivité et blessé par le dispositif d'attache.

Tout récemment, à la suite du développement de l'épizootie de botulisme de type $C$ constatée dans le nord du Sénégal, il est apparu que l'importance des affections animales dues aux germes anaérobies dépassait le cadre étroit qui lui semblait dévolu jusqu'alors.

Le présent article a pour but de rapporter l'observation de cas d'entérite aıguë hémorragique provoqués par Welchia perfringens chez des zébus gobra. Ces accidents sont survenus dans un ranch privé situé à une quarantaine de kilomètres de Dakar.

\section{COMMÉMORATIFS — SYMPTOMES}

Le 11 mai 1966, un troupeau d'une cinquantaine de têtes de zébus gobra adultes est acheté par le propriétaire d'un ranch à des éleveurs nomades en déplacement. Ces anımaux sont destinés à l'engraissement avant d'être livrés à la boucherie. L'exploitation possède une tuerle particulıère et deux magasıns de vente à Dakar.

Les bovins sont placés temporairement dans un corral dépourvu de toute végétation. $\mathrm{De} \mathrm{I}_{\mathrm{a}}$ 
paille d'arachide est disposée en quantité suffisante sur le sol et l'abreuvement est assuré deux fois par jour.

Le 13 mai, les premiers symptômes apparaissent. Certains individus prennent une attitude figée, des tremblements légers sont constatés en même temps que s'installe une diarrhée sanglante. La température demeure voisine de la normale. Dans la nuit deux sujełs succombent.

A la suite d'une visite effectuée le 14 au matin, un animal partıculièrement atteint est abattu sur notre demande. Des prélèvements sont effectués et transportés sous glace au Laboratorre. Au cours d'une seconde visite accomplie l'aprèsmidi, nous constatons que la presque totalıté du troupeau manifeste des signes de l'affection, soit environ 45 malades. Un zébu présente une diarrhée sanglante profuse il est abattu devant nous et de nouveaux prélèvements sont recueillis.

L'entreprise au sein de laquelle est située le corral traite de nombreux arbres frultiers à l'aide de composés chımıques divers aussi la possibilité d'une intoxication est momentanément retenue.

\section{LÉSIONS}

L'autopsie des animaux abattus sur notre demande permet de noter : des suffusions sanguines sous-cutanées légères, une congestion peu marquée du poumon ef une congestion intense du foie. Au niveau de l'intestın, la lumière est presque totalement remplie de caillots noirâtres et de sang en nature, la muqueuse présente un caractère hémorragique des plus accentués.

\section{ÉVOLUTION}

Environ 15 bovins succombent dans les jours qui suivent. A la suite des examens bactériologiques, la paille d'arachide est retirée de la ration et le troupeau est envoyé en brousse. Les animaux survivants se sont progressivement rétablis: après guérison, ils ont été livrés à la boucherie.

\section{BACTÉRIOLOGIE}

Du foie, du rein et du contenu intestinal des deux bovins sacrifiés, a été isolé Welchia per- fringens. L'hémoculture, en bovillon viande-foie glucosé à 2 p. 1.000, du sang du cœur fournit une culture pure du germe, ce qui signe la bactériémie,

Le typage effectué à l'Institut Pasteur de Paris révèle que la souche appartient au type $A$. Elle s'avère très pathogène pour le cobaye inoculé par vole intra-musculaire; $0,20 \mathrm{ml}$ d'une culture en bouillon VF de 24 heures entraîne la mort en moins de 18 heures. La toxine produite $n$ 'hémolyse que très faiblement une suspension d'hématies de mouton à 5 p. 100.

\section{DISCUSSION}

Le rôle des alıments dans l'étiologie des gastroentérotoxémies foudroyantes est bien connu. MORAILLON et YALCIN (2) mentionnaient récemment parmi les causes favorisantes : l'excès de matières protéiques, les brusques changements d'alimentation, les moisissures alimentaires etc... Ces auteurs, après avoir rappelé les travaux de PREVOT et THOUVENOT (5), émettent I'hypothèse que la brusque extension des affections entérotoxémiques constatée en France pourrait bien être en rapport avec la consommation d'aliments du bétail ef de poudre de lait soullés par Weichia perfringens ou d'autres ancérobies par incorporation de prodults polivés d'origine anımale (farine de viande et de poisson, poudre d'os etc...) ou végétale (orge, farıne de luzerne etc...).

Des granulés alimentaires du bétal renferment parfois des quantités massives de Welchia perfringens (de 10.000 à 3.000 .000 de germes par gramme). MORAILLON et YALCIN voient dans la technique de stérilisation des cadavres d'animaux ordınairement pratiquée dans les centres d'équarrissage la cause de la pullution des germes anaérobies.

Lors de notre seconde visite effectuée dans le ranch où sévissait l'infection nous avons examiné le stock de paille d'arachide, il nous estapparu fort ancien et partiellement mossi. A partır d'échantillons, nous avons pu procéder à l'isolement de Welchia perfringens ou type A. Cette souche était peut-être responsable de la maladie survenue parmi les zébus tout récemment introduits dans l'exploitation. Quoi qu'il en soit la suppression de la paille diarachide de la ration et la 
mise au pâturage de brousse du troupeau ont permis de limiter les pertes.

L'apparition de ces cas d'entérites hémorragique aiguè à Welchia perfringens montre qu'en Afrique, il est encore possible de se trouver en présence d'une pathologie nouvelle. II est bon d'avoir ce fait présent à l'esprit lorsque l'on sait que les autorités responsables envisagent de développer l'élevage de races laitières en stabu- lation en utilisant les sous-prodults des industries alımentaires sénégalaises.

Instifut d'Elevage et de Médecine vétérinaire des Pays tropicoux, Moisons-Alfort.

Laborotore national de l'Elevage et de Recherches vétérinaires, DakarHann.

\section{SUMMARY}

Acute haemorrhagic enteritis associated with Welchio perfringens in zebu cattle in Senegal

Cases of acute haemorrhagic enteritis with Weichia perfringens type A suddenly occurred in aduit Gobra zebus introduced in a ranch where they had to be fattened before to be slaughtered. In a herd of about 50 animals, 17 died of this disease. The isolated stroin was very pathogen for the guinea-pig by intramuscular way and the culture toxin was not very hemolytic for the sheep erythrocytes. The feeding with old and partly mouldy pea-nut straw is believed the cause of this disease.

\section{RESUMEN}

Enteritis hemorrágica aguda con Welchia perfringens en cebúes de Senegal

Casos de enteritis hemorrágica aguda con Welchı perfringens o tipo A ocurrieron súbitamente en cebúes gobra adultos introducidos en un rancho para ser engordados en ello antes de la matanza. En una manada de unas 50 reses, 17 de ellas sucumbieron a esta enfermedad. Se mostró muy patogena para el cobayo la cepa aislada, admınistrada por via intramuscular, y pora las hematias de la oveja la toxina de cultivo poco hemolítica. A lo que parece, el consumo de paja de cacahuete, vieja y parcialmente mohosa es causa de dicho enfermedad.

\section{BIBLIOGRAPHIE}

1. BOZEMAN (C. S.), LINDLEY (W. H.), BRANSON (J. W.). - Bovine enterotoxemia. J. Amer, vet. Med. Ass., 1962, 140 (9), 937942.

2. MORAILLON (P.) et YALCIN (N.). - Formes nouvelles de gastro-entéro-hépatotoxémies et rôle étiologique des aliments du bétail. Rec. Méd. vét., 1966, 142 (10), 935-947.

3. PESCE DE FAGONDE (A.). - Enteroxae- mia in cattle caused by Clostridium perfringens. Rev. Med. vet., B. Aires, 1964, 45, 97-107.

4. PREVOT (A. R.), JACOTOT (H.) et VALLÉE (A.). - Recrudescence des infections animales à Weichia perfringens A. Bull. Acod. vél. de France, 1961, 34 (7), 267.

5. PREVOT (A. R.) ef THOUVELOT (H.). Le lait peut-il transmettre les maladies anaérobies? Ann. Instifut Pasteur, 1952, 83, 180-185. 